\title{
Rhinoscleroma causing severe bilateral nasal obstruction
}

Authors

Mário Augusto Pinto de Moraes, MD

Albino Verçosa de

Magalhães, $\mathrm{MD}^{1}$

Larissa Cardoso Marinho, $\mathrm{MD}^{1}$

Ana Emília Borges de Azevedo, MD

Fabiana Pirani Carneiro, $\mathrm{MD}^{1}$

Igor Teixeira Raymundo $\mathrm{MD}^{2}$

'Department of Pathology, Hospital Universitário de Brasília, Brasília, Brazil.

${ }^{2}$ Department of

Otorhinolaryngology, Hospital Universitário de

Brasília, Brasília, Brazil.

Submitted on: 09/27/2009 Approved on: 11/03/2009

Correspondence to: Fabiana Pirani Carneiro, M.D.

Centro de Anatomia Patológica

Hospital Universitário de Brasília, UNB

Via L2 Norte, SGAN 604/605, Módulo C

Brasília - DF - Brasil. CEP: 70840-050

Phone: 5561 - 34485499

E-mail:

fabianapirani@hotmail.

We declare no conflict of interest.

\begin{abstract}
Rhinoscleroma is a chronic, infectious and granulomatous disease of the respiratory tract. There is often a delay in diagnosis due to unfamiliarity with the disease and also because culture is not always positive. We report a case in a 26-year-old woman with granular mass obstructing bilateral nasal cavities and causing breathing difficulty. Histopathological examination showed characteristic Mikulicz histiocytes containing numerous Gram-negative intracellular rod-shaped bacilli consistent with the diagnosis of rhinoscleroma. The patient was treated with gemifloxacin and tetracycline and remains asymptomatic over a year follow-up period. It is important to consider rhinoscleroma in cases of chronic nasal obstruction. As culture is not always positive, histopathological examination may be crucial to the diagnosis.
\end{abstract}

Keywords: rhinoscleroma, nasal obstruction, histopathology.

[Braz I Infect Dis 2010;14(2):190-192] @Elsevier Editora Ltda.

\section{INTRODUCTION}

Rhinoscleroma is an unusual chronic granulomatous disease that usually affects the respiratory tract mucosa and is caused by Klebsiella rhinoscleromatis, a Gram-negative rod-shaped bacteria. ${ }^{1}$ Most of the cases have been reported from many countries of the Middle East, tropical Africa, India, south-east Asia, Central and South America but, in recent years, some cases in nonendemic areas have been reported because of the increased migration of the population over the world. ${ }^{2,3}$ We found few isolated cases described in Brazilian patients. ${ }^{4-8}$ However, more than 16,000 cases have been reported from different parts of the world since $1960 .^{1}$ We reported a case of rhinoscleroma causing severe bilateral nasal obstruction which diagnosis was based on characteristic histological findings.

\section{CASE REPORT}

A 26-year-old Brazilian woman presented with a 2-year history of mucopurulent nasal discharge, nasal obstruction, epistaxis and headache. Examination of the nose revealed synechia obstructing bilateral nasal vestibules and septal deviation. The patient was submitted to septoplasty and presented symptomatic improve- ment. One year after surgery, she returned with the same complains and presenting, on examination of the nose, a granular mass obstructing bilateral nasal cavities (Figure 1). Computed tomography revealed bilateral soft-tissue mass located in the nasal cavities without extension into the paranasal sinuses. An incisional biopsy was performed to establish the diagnosis. Histopathological examination revealed a diffuse

Figure 1: (A) e (B) Granular mass obstructing bilateral nasal cavities.

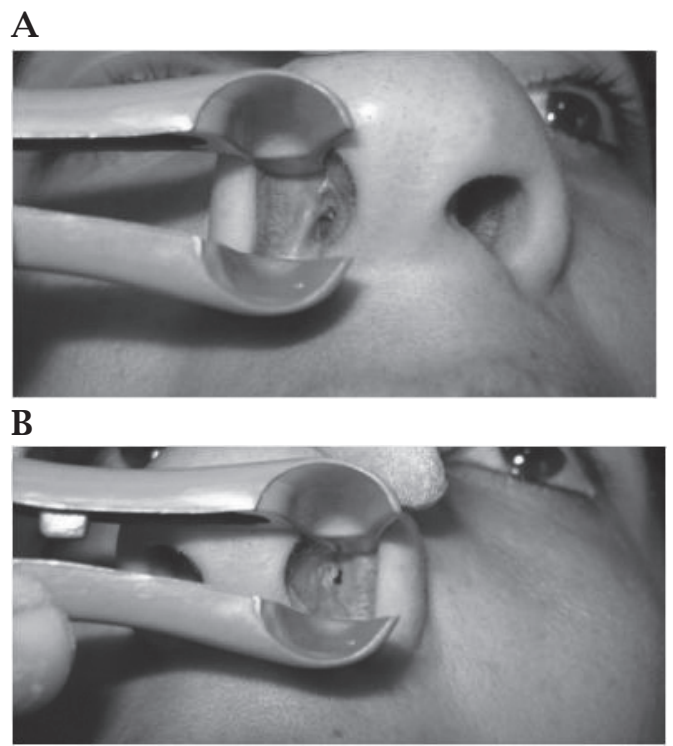


Figure 2: Histopathological examination. (A) Diffuse inflammatory infiltrate (HE, 25x). (B) Large foamy macrophage (Mikulicz cells) and mononuclear cells (HE, 400x). (C) Rod-shaped bacilli inside macrophage (Warthin Starry stain, 1000x).

A

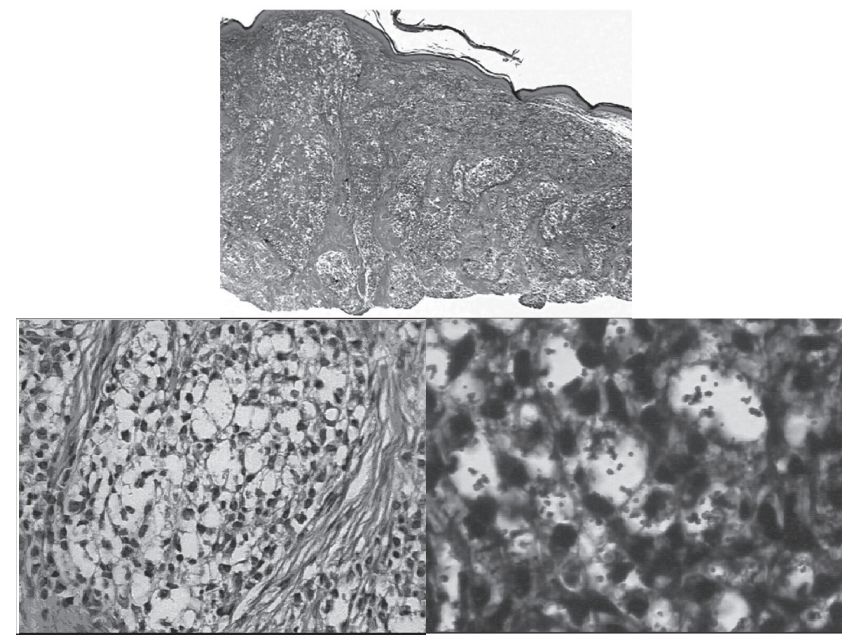

inflammatory infiltrate predominantly of mononuclear cells with large foamy macrophage containing small rodlike bacteria. These organisms were Gram-negative and stained with both Warthin-Starry and periodic acid-Schiff stains (Figure 2). Acid-fast bacilli stain was negative for microorganisms. Treatment with tetracycline $(500 \mathrm{mg}-6 / 6 \mathrm{~h}$ for 1 month) and gemifloxacin (320 mg/day for 2 weeks) was followed by significant symptomatic improvement, but a discrete stenosis in nasal cavity persisted. One year after the treatment, the patient remains asymptomatic.

\section{DISCUSSION}

The diagnosis of rhinoscleroma requires a high index of suspicion and clinicopathological correlation. ${ }^{9}$ This disease is more frequent in middle aged women, living with poor hygienic and nutritional condition. ${ }^{10}$ Cellular immunity may be impaired in affected patients; however, our patient was immunocompetent. ${ }^{11}$ The symptoms are nonspecific such as mucopurulent rhinorrhea, cough, breathing difficulty due to nasal obstruction, dysphonia, epistaxis and headache. ${ }^{12,13}$

Three overlapping stages were described in rhinoscleroma: catarrhal-atrophic, granulomatous (proliferative or nodular) and sclerotic (cicatricial or fibrotic). ${ }^{2}$ Microscopically, the catarrhal/atrophic stage exhibits squamous metaplasia and a nonspecific subepithelial infiltrate of polymorphonuclear leukocytes with granulation tissue. The diagnostic features are found in the granulomatous stage. The histologic hallmark for diagnosis of rhinoscleroma is the subepithelial presence of Mikulicz cells, large vacuolated macrophages containing rod shaped bacilli. The sclerotic stage displays extensive fibrosis, which may lead to stenosis and disfiguration. Biopsies of the fibrotic stage may be quite nonspecific. In present case, the patient was in granulomatous stage since numerous Mikulicz cells were found.
The differential diagnosis includes mainly several infectious granulomatous processes: bacterial (tuberculosis, actinomycosis, syphilis, and leprosy), fungal (histoplasmosis, paracoccidioidomycosis, and sporotrichosis) and parasitic (mucocutaneous leishmaniasis). ${ }^{14}$ Rhinoscleroma also should be distinguished from Wegener granulomatosis, lymphomas and carcinomas. Specific diagnosis is made by identification in biopsy samples of histopathologic features and rod-shaped bacilli that are positive to periodic acidSchiff (PAS) and Warthin-Starry stain. Immunoperoxidase staining with anticapsular antisera has also proved useful. Bacterial culture (blood or MacConkey agar) is positive in only $50 \%$ of the cases. ${ }^{15}$

Rhinoscleroma is a slowly progressive disease characterized by periods of remission and relapse. Early diagnosis and prolonged therapy are critical to avoid recurrence and late sequelae. In previous study, oxytetracycline and ciprofloxacin were used with good results and without relapse during six to 12 months of follow-up. ${ }^{2}$ Untreated patients tend to progress to involvement of other parts of the respiratory system. In trachea the disease can lead to progressive airway obstruction, a life-threatening complication. ${ }^{16}$ Mortality from rhinoscleroma is extremely rare, resulting from upper airway obstruction in patients with undiagnosed disease or as a complication of a surgical procedure.

\section{CONCLUSION}

It is important to consider rhinoscleroma in cases of chronic nasal obstruction. As culture is not always positive, histopathological examination may be crucial to the diagnosis.

\section{REFERENCES}

1. Hart CA, Rao SK. Rhinoscleroma. J Med Microbiol 2000; 49:395-6.

2. Maguiña C, Cortez-Escalante J, Osores-Plenge F et al. Rhinoscleroma: eight Peruvian cases. Rev Inst Med Trop Sao Paulo 2006; 48:295-9.

3. Andraca R, Edson RS, Kern EB. Rhinoscleroma: a growing concern in the United States? Mayo Clinic experience. Mayo Clin Proc 1993; 68:1151-7.

4. Simons ME, Granato L, Oliveira RC, Alcantara MP. Rhinoscleroma: case report. Braz J Otorhinolaryngol 2006; 72:568-71.

5. Granato L, Jorge Jr JJ, Souza DG, França LCM. RinoscleromaConsiderações sobre um caso. Revista Brasileira de Otorrinolaringologia 1977; 43:1-11.

6. Oliveira HF, Carvalho ASPA, Argollo NCS, Neves CA, Dossi MO. Rinoscleroma e Linfoma não-Hodgkin Nasal. Intl Arch Otorhinolaryngol 2009; 13:96-8.

7. Mello LR, Albertino S, Tonon S. Rinoscleroma-tratamento cirúrgico. Rev Col Bras Cir 1984; 11:125-9.

8. Barbosa AA, Teixeira JC, Andrade JS. Esclerona (rinoscleroma). An Fac Med Univ. Fed Minas Gerais 1985; 34:217-21.

9. Stiernberg CM, Clark WD. Rhinoscleroma: a diagnostic challenge. Laryngoscope 1983; 93:866-870. 
10. Casanova JL. Rhinoscleroma: a French national retrospective study of epidemiological and clinical features. Clin Infect Dis 2008; 47:1396-402.

11. Berron P, Berron R, Ortiz-Ortiz L. Alterations in the T-lymphocyte subpopulation in patients with rhinoscleroma. J Clin Microbiol 1988; 26:1031-3.

12. Shum TK, Whitker CW, Meyer PR. Clinical update on rhinoscleroma. Laryngoscope 1982; 92:1149-55.

13. Abalkhail A, Satti MB, Uthman MA et al. Rhinoscleroma: a clinicopathological study from the Gulf region. Singapore Med J 2007; 48:148-51.
14. Fuchs HA, Tanner SB. Granulomatous disorders of the nose and paranasal sinuses. Curr Opin Otolaryngol Head Neck Surg 2009; 17:23-7.

15. Meyer PR, Shum TK, Becker TS, Taylor CR. Scleroma (Rhinoscleroma). A histologic immunohistochemical study with bacteriologic correlates. Arch Pathol Lab Med 1983; 107:377-83.

16. Yigla M, Ben-Izhak O, Oren I, Hashman N, Lejbkowicz F. Laryngotracheobronchial involvement in a patient with nonendemic rhinoscleroma. Chest 2000; 117:1795-8. 